\title{
Haemoglobin and haematocrit: the threefold conversion is also non valid for assessing anaemia in Plasmodium vivax malaria-endemic settings
}

\author{
Alfonso J Rodríguez-Morales ${ }^{1}$, Elia Sánchez², Melissa Arria ${ }^{3}$, Miguel Vargas², \\ Carmelina Piccolo ${ }^{2}$, Rosa Colina ${ }^{2}$ and Carlos Franco-Paredes*4,5
}

Address: ${ }^{1}$ Instituto Experimental José Witremundo Torrealba, Universidad de Los Andes, Trujillo 3102, Venezuela, ${ }^{2}$ Infectious Diseases Service, Hospital Santos Anibal Dominicci, Carúpano, Sucre, Venezuela, ${ }^{3}$ Postgraduate Course on Genetics, Venezuelan Institute for Scientific Research (IVIC), Caracas, Venezuela, ${ }^{4}$ Division of Infectious Diseases, Emory University School of Medicine, TravelWell Clinic 550 Peachtree Street, MOT CLH, Atlanta GA, 30308, USA and ${ }^{5}$ Hospital Infantil de México, Federico Gómez, México DF, México

Email: Alfonso J Rodríguez-Morales - ajrodriguezm_md@hotmail.com; Elia Sánchez - ddose@cantv.net; Melissa Arria - meliarria@saludfmv.org; Miguel Vargas - venvirology98@hotmail.com; Carmelina Piccolo - bacteroides79@ hotmail.com; Rosa Colina - rcolina@cantv.net; Carlos Franco-Paredes* - cfranco@sph.emory.edu

* Corresponding author

Published: 17 December 2007

Malaria Journal 2007, 6:166 doi:10.1186/1475-2875-6-166
Received: 8 June 2007

Accepted: 17 December 2007

This article is available from: http://www.malariajournal.com/content/6/1/166

(C) 2007 Rodríguez-Morales et al; licensee BioMed Central Ltd.

This is an Open Access article distributed under the terms of the Creative Commons Attribution License (http://creativecommons.org/licenses/by/2.0), which permits unrestricted use, distribution, and reproduction in any medium, provided the original work is properly cited.

\begin{abstract}
It has been recently reported that the standard threefold conversion from haematocrit to haemoglobin underestimates the prevalence of anaemia and low levels of haemoglobin in children living in areas endemic for Plasmodium falciparum malaria. The data presented herein describes the experience in a malaria-endemic zone in northeastern Venezuela (state of Sucre), where a similar bias between haematocrit and haemoglobin in patients with Plasmodium vivax infection was found. In summary, the relationship between haematocrit and haemoglobin needs to be specifically evaluated according to each particular region or epidemiological setting.
\end{abstract}

\section{Background}

Carneiro et al [1] recently reported that the standard threefold conversion from haematocrit to haemoglobin underestimates the prevalence of anaemia and low levels of haemoglobin in children under five years of age in malaria endemic settings.

In agreement with Carneiro et al findings, demonstrating that the usual threefold conversion represents a significant bias when haemoglobin $(\mathrm{Hb})$ is estimated based on haematocrit (Hct) values in children with malaria, the present report describes the experience in a vivax malaria-endemic zone in northeastern Venezuela. It has been a widely accepted assumption that this conversion could be used as an alternative measurement to haemoglobin in malaria studies [2]. This is particularly important in African settings where Plasmodium falciparum malaria is endemic, but the corresponding haemoglobin levels cannot be derived with an acceptable accuracy using the value three as a conversion factor [2]. As a consequence, the relationship between haematocrit and haemoglobin needs to be specifically evaluated according to each particular region or epidemiological setting. In order to illustrate this important issue, the experience in a malaria-endemic zone in northeastern Venezuela (state of Sucre) is described [3,4], showing a similar bias between haematocrit and haemoglobin in patients with Plasmodium vivax infection. 


\section{Methods and results}

Data from one study that have measured haemoglobin and haematocrit was used to assess the reliability of the standard threefold conversion factor. Finger-prick blood samples were collected for determination of anaemia status from 120 patients with malaria aged 4-89 years-old from a prospective survey carried out between 2000 and 2002 in Carupano, Sucre, Venezuela [5]. In this study, haemoglobin concentration was assessed by haemophotometry and haematocrit was assessed by centrifugation using standard procedures for microhaematocrit tubes and centrifuge (i.e. 10 minutes at a fixed speed of 11,000 rpm).

\section{Statistical methods}

As described by Carneiro et al [1], the measurement of observed and estimated haemoglobin using the method of plotting the difference between the measures against the mean of the two measures, as reported by Bland \& Altman [6], is compared. Then, a comparison between haemoglobin $(\mathrm{g} / \mathrm{dl})$ and haematocrit $(\%)$ divided by a factor of three was done to be able to compare the measurements on approximately the same scale ("grams of haemoglobin per $\mathrm{dl} ")$. The difference between the haemoglobin and haematocrit/3 measurements (i.e. $\mathrm{Hb}$ $\mathrm{Hct} / 3$ ) and the mean of the two measurements (i.e. ( $\mathrm{Hb}+$ $\mathrm{Hct} / 3) / 2$ - now called average to avoid confusion with mean difference), were calculated for each individual. Linear regression analyses were used to define the relation- ship between the mean difference and the average of the two measures [6], adjusting for a priori covariates of age and sex. The differences between both measures were also tested in terms of means comparison using the Student's $t$ test for one-sample, for independent-samples and pairedsamples.

Haemoglobin measurements were lower than haematocrit/3 in this study in $92.5 \%(111 / 120)$, with a linear trend in the relationship so that more negative differences were seen with increasing haemoglobin levels $\left(r^{2}=\right.$ $0.1379, \mathrm{~F}=18.87, \mathrm{P}<0.0001$ ) (Figure 1). Logarithmic transformations of the means and differences as suggested by Bland \& Altman [7] did not improve this relationship.

The mean difference between haemoglobin and haematocrit/ 3 values was $-0.6( \pm 0.4$, range -1.6 to 0.5$)$. The differences between both measures in terms of means comparison for Student's $t$ tests were also significantly different (Table 1). When the haematocrit was calculated using the haemoglobin (haemoglobin $\times 3$ ), similar significant $(\mathrm{P}<0.05)$ differences were evidenced between the observed and estimated haematocrit. These differences not showed a statistically significant variation in regard to the age neither with the sex $(\mathrm{P}>0.05)$.

Then, the relation between observed haematocrit and observed haemoglobin was modelated (Figure 2$)(\mathrm{y}=$ $3.1906 x-0.6215)$. The final regression model gave the
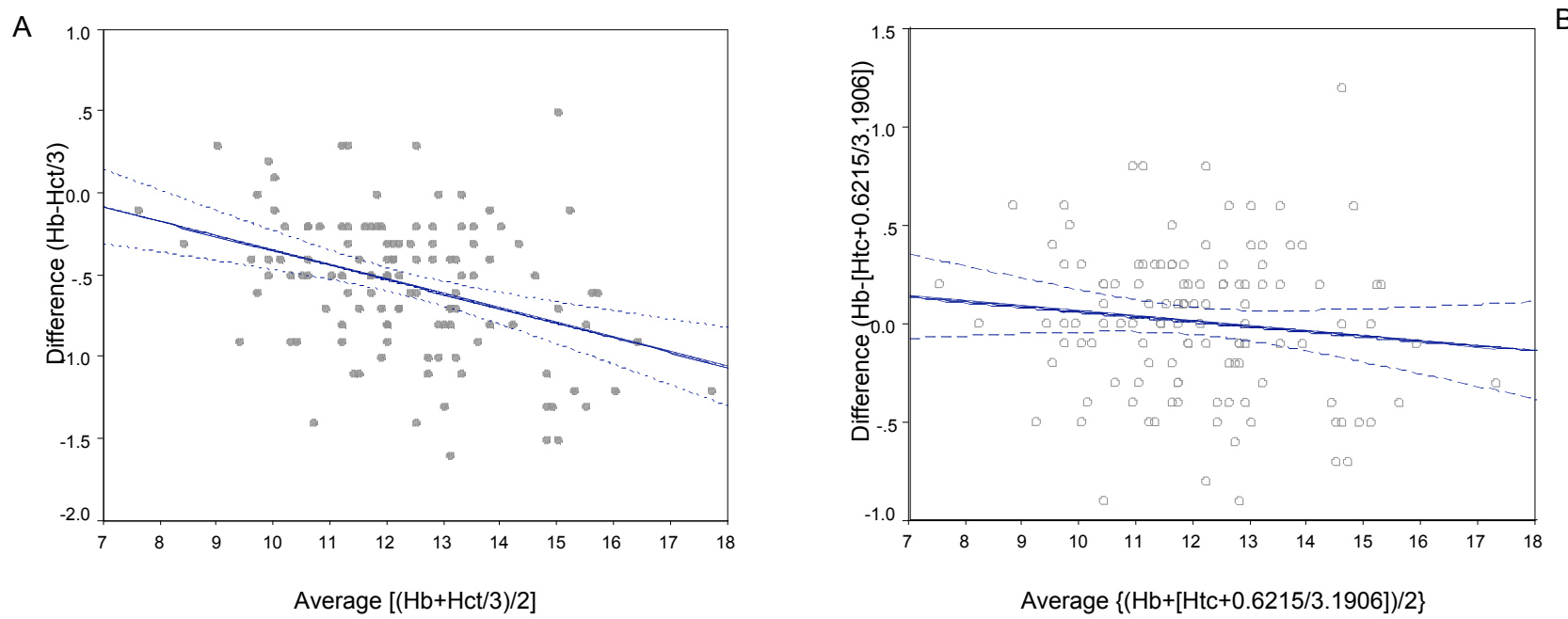

Figure I

Scatter-plots of difference against average of haemoglobin and haematocrit/3 (A), as well after correction using (haematocrit+0.62 I5)/3.1906 (B). Scatter-plots of difference against average of haemoglobin and haematocrit/3 for paired measurements, and between average of haemoglobin and (haematocrit+0.6215)/3.1906. The line of best fit (blue) indicates the trend towards greater differences at higher haemoglobin values (significantly lower after correction). Both axes are in "grams of haemoglobin/dl". 
Table I: Mean difference comparisons between observed haemoglobin and estimated haemoglobin (Haematocrit/3, expressed as " $\mathrm{g}$ of haemoglobin/dl")

\begin{tabular}{|c|c|c|}
\hline & Observed Haemoglobin $(n=120)$ & Estimated Haemoglobin (Haematocrit/3) $(n=120)$ \\
\hline Mean & 12.06 & 12.62 \\
\hline Standard deviation & 1.71 & 1.87 \\
\hline Standard error & 0.16 & 0.17 \\
\hline \multicolumn{3}{|l|}{ One-sample test } \\
\hline $\mathrm{t}$ & 77.23 & 73.94 \\
\hline Mean difference & 12.06 & 12.62 \\
\hline $95 \% \mathrm{Cl}$ of the difference & 11.75 to 12.37 & 12.28 to 12.95 \\
\hline $\mathrm{P}$ & $<0.001$ & $<0.001$ \\
\hline \multicolumn{3}{|l|}{ Independent-sample test } \\
\hline $\mathrm{t}$ & - & -2.399 \\
\hline Mean difference & - & -0.555 \\
\hline $95 \% \mathrm{Cl}$ of the difference & - & -1.017 to $-9.9328 \mathrm{E}-02$ \\
\hline $\mathrm{P}$ & - & 0.017 \\
\hline \multicolumn{3}{|l|}{ Paired-sample test } \\
\hline $\mathrm{t}$ & - & -14.284 \\
\hline Mean difference & - & -0.555 \\
\hline $95 \% \mathrm{Cl}$ of the difference & - & -0.6319 to -0.478 । \\
\hline$P$ & - & $<0.001$ \\
\hline
\end{tabular}

following relationship, which represents the line of best agreement between the two measures $\left(r^{2}=0.9526, \mathrm{~F}=\right.$ 2372.0, $\mathrm{P}<0.0001)$ :

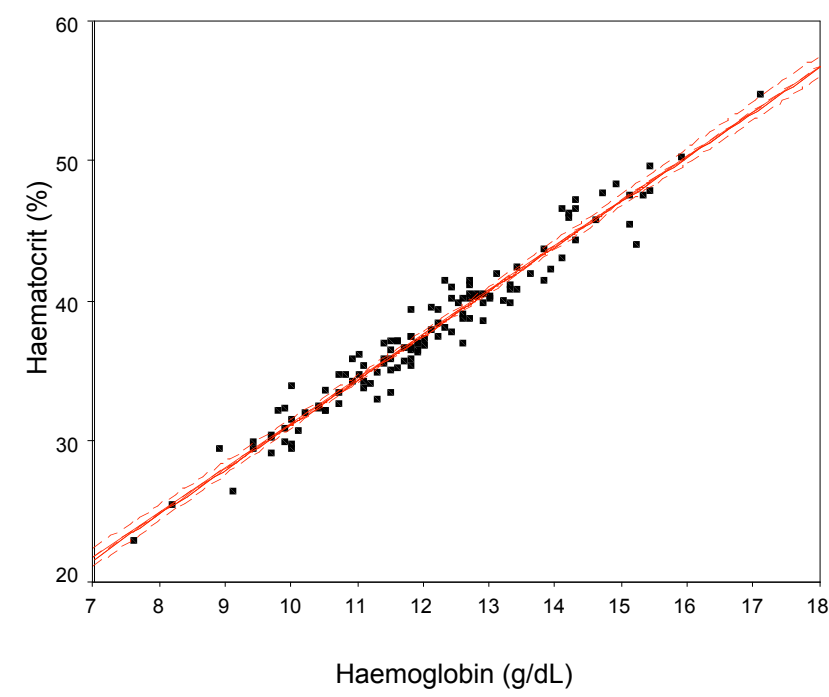

Figure 2

Scatter-plot of the observed haemoglobin and observed haematocrit relations. The line of best fit (red) indicates a trend towards higher haemoglobin and haematocrit values, giving the following Equation I: Estimated Haemoglobin $=($ Haematocrit + 0.6215)/3.1906.
Estimated Haemoglobin $=($ Haematocrit +0.6215$) /$

$$
3.1906 \text { (1) }
$$

When the estimation of haemoglobin using this model was corrected, the new estimated haemoglobin ([Haematocrit +0.6215$] / 3.1906)$ shown that the haemoglobin measurements were lower than corrected observed haemoglobin in $49.2 \%(59 / 120)$, with a linear trend in the relationship significantly more slight than the original $\left(r^{2}\right.$ $=0.013, \mathrm{~F}=1.55, \mathrm{P}=0.216$ ) (Figure 1 ).

\section{Discussion}

These results showed a consistent bias of haemoglobin measurements to indicate a greater degree of anaemia than haematocrit measurements in the same individuals and populations if the standard threefold conversion is used, as has been reported previously [8], and most recently by Carneiro [1].

The difference between the haemoglobin and centrifuged haematocrit/3 was found to be non-uniform, decreasing with average values of these measures, but conversely not significantly modified by age or sex. These results suggest that the relationship between haemoglobin and centrifuged haematocrit could be independent to the recent exposure to malaria, which is a continuous risk in endemic settings.

Both Hct and Hgb levels could be affected by factors such as the method and equipment used for its determination, 
environment or subject's differences that may cause a spurious change in the measured value and lead to inaccuracies $[2,9]$.

These and previous data $[1,2]$ have shown that Hgb levels cannot be derived from the Hct values with an acceptable accuracy using the general rule of dividing by 3 . The relationship between Hgb and Hct is not exactly 3 and could be affected by age, sex, infection status, malarial etiology and season, among other factors. Due to the lack of agreement, the commonly assumed 'equivalent' cutoff points for anaemia definitions need to be re-evaluated. More information is needed for different aetiologies of anaemia.

\section{Conclusion}

The present study demonstrates that the standard threefold conversion from haematocrit to haemoglobin underestimates the prevalence of anaemia and low levels of haemoglobin in children and adults in a Plasmodium vivax malaria endemic settings. In contrast to the results of Carneiro et al [1], it was found that the bias was less acute for more severe anaemia defined by haemoglobin $<8 \mathrm{~g} / \mathrm{dl}$ and haemoglobin<5 g/dl.

\section{Competing interests}

The author(s) declare that they have no competing interests.

\section{Authors' contributions}

AJRM analysed and interpreted the data, and wrote the first draft of the paper. CFP designed and co-ordinated the original studies, contributed to data interpretation and to drafting and revising the manuscript. ES, MA, MV, CP and $\mathrm{RC}$ were involved in data collection and critically revised the manuscript. All authors read and approved the final manuscript.

\section{Acknowledgements}

Sources of funding for this study CFP: Hospital Infantil de Mexico, Federico Gomez, Mexico contributed to the publication fee; AJRM: Colegio Médico del Distrito Metropolitano de Caracas, Venezuela contributed to the original studies funding and presentation at meetings.

\section{References}

I. Carneiro IA, Drakeley C], Owusu-Agyei S, Mmbando B, Chandramohan D: Haemoglobin and haematocrit: is the threefold conversion valid for assessing anaemia in malaria-endemic settings? Malar J 2007, 6:67.

2. Quinto L, Aponte JJ, Menendez C, Sacarlal J, Aide P, Espasa M, Mandomando I, Guinovart C, Macete E, Hirt R, Urassa H, Navia MM, Thompson R, Alonso PL: Relationship between haemoglobin and haematocrit in the definition of anaemia. Trop Med Int Health 2006, I I:1295-1302.

3. Rodriguez-Morales AJ, Sanchez E, Arria M, Vargas M, Piccolo C, Colina R, Franco-Paredes C: White blood cell counts in Plasmodium vivax malaria. J Infect Dis 2005, I 92:1675-1676. author reply 1676-1677.
4. Rodriguez-Morales AJ, Sanchez E, Vargas M, Piccolo C, Colina R, Arria $M$ : Anemia and thrombocytopenia in children with Plasmodium vivax malaria. J Trop Pediatr 2006, 52:49-5I.

5. Rodriguez-Morales AJ, Sanchez E, Vargas M, Piccolo C, Colina R, Arria $M$, Franco-Paredes $C$ : Occurrence of thrombocytopenia in Plasmodium vivax malaria. Clin Infect Dis 2005, 41:130-131.

6. Bland JM, Altman DG: Measuring agreement in method comparison studies. Statistical Methods in Medical Research 1999, 8:135-160.

7. Bland JM, Altman DG: Statistical methods for assessing agreement between two methods of clinical measurement. Lancet 1986, i:307-310.

8. Graitcer PL, Goldsby JB, Nichaman MZ: Hemoglobins and hematocrits: are they equally sensitive in detecting anemias? $\mathrm{Am} J$ Clin Nutr 198I, 34:6I-64.

9. Keen ML: Hemoglobin and hematocrit: an analysis of clinical accuracy. Case study of the anemic patient. ANNA journall American Nephrology Nurses' Association 1998, 25:83-86.

\section{Publish with Bio Med Central and every scientist can read your work free of charge}

"BioMed Central will be the most significant development for disseminating the results of biomedical research in our lifetime. "

Sir Paul Nurse, Cancer Research UK

Your research papers will be:

- available free of charge to the entire biomedical community

- peer reviewed and published immediately upon acceptance

- cited in PubMed and archived on PubMed Central

- yours - you keep the copyright

Submit your manuscript here:

http://www.biomedcentral.com/info/publishing_adv.asp
BioMedcentral 